\title{
Origin of unusual catalytic activities of Au-based catalysts
}

\author{
Young Dok Kim *, Matthias Fischer, Gerd Ganteför \\ Department of Physics, University of Konstanz, Universitaetsstrasse 10, D-78464 Konstanz, Germany
}

\begin{abstract}
Experimental evidences for the non-dissociative chemisorption of $\mathrm{O}_{2}$ are presented on even-numbered free $\mathrm{Au}$ anion clusters $\left(\mathrm{Au}_{n}^{-}, n=\right.$ number of atoms) up to $\mathrm{Au}_{20}^{-}$at room temperature. Our result indicates that the formation of the activated di-oxygen species is the key of the unusual catalytic activities of Au-based catalysts. No correlation between geometrical structures of $\mathrm{Au}_{n}^{-}$and the activities towards $\mathrm{O}_{2}$ adsorption was found, showing that site-specific chemistry disappears for Au-nanocatalysis. We demonstrate that interplay between cluster physics and surface chemistry is a promising strategy to unveil mechanisms of elementary steps in nanocatalysis.
\end{abstract}

\section{Introduction}

Pioneering works of Haruta, Goodman and many other scientists [1-7] in the last decade have shown that oxide-supported gold $\mathrm{(Au}$ ) particles, which are inert as bulk form, become extraordinarily active for various chemical reactions with a cluster size below two to three nanometers. The unusual size-dependent catalytic behaviors of $\mathrm{Au}$ clusters are currently one of the most widely treated subjects in chemistry and physics [1-23]. However, the origin of the exceptional catalytic properties of $\mathrm{Au}$ nanoclusters is still questionable. For $\mathrm{O}_{2}$ adsorption on $\mathrm{Au}$ particles, which is responsible for the cluster-size effects of Au-based catalysts, various adsorption structures such as

\footnotetext{
${ }^{*}$ Corresponding author. Fax: +49753188-3888.

E-mail address: young.kim@uni-konstanz.de (Y.D. Kim).
}

dissociative adsorption and the formation of superoxo-species and peroxo-species have been under consideration [3,7-12]. However, no generally accepted picture for the $\mathrm{O}_{2}$ adsorption on Au-nanoclusters has appeared yet.

Combination of density functional theory (DFT)-calculations and various spectroscopic experiments concluded that the electron transfer from oxide supports to $\mathrm{Au}$ is crucial for the high catalytic activities [7]. The mass-selected Au anion clusters $\left(\mathrm{Au}_{n}^{-}, n=\right.$ number of gold atoms) in the gas phase show comparable catalytic activities to those of oxide-supported $\mathrm{Au}$ particles, confirming the importance of the negative charge on $\mathrm{Au}$ clusters for catalytic activities [10]. Investigations on gas phase clusters are advantageous, since the mass of free anion cluster is better controlled with respect to the deposited clusters, allowing studies on cluster-size dependence for the electronic, geometric and chemical properties with an atomic 
precision. Thus, $\mathrm{Au}_{n}^{-}$in the gas phase was suggested to be used as model systems to unveil reaction mechanisms of Au-nanocatalysts [9-11].

In this Letter, we open a new insight into the elementary chemisorption steps on Au-nanocatalysts using experimental techniques of cluster physics. We found that $\mathrm{O}_{2}$ molecularly adsorb on $\mathrm{Au}_{n}^{-}$with $n=$ even numbers up to $\mathrm{Au}_{20}^{-}$at room temperature (with an exception for $\mathrm{Au}_{16}^{-}$, which is inert towards $\mathrm{O}_{2}$ chemisorption). Our results suggest that the di-oxygen species are important reaction intermediates for catalytic reactions on Au-based catalysts. We found that the most important criterion for strong interaction with $\mathrm{O}_{2}$ for $\mathrm{Au}$ anion cluster is a low electron affinity. It is remarkable that the anion of $\mathrm{Au}_{20}$, a 'magic' cluster with a large gap between the highest occupied molecular orbital (HOMO) and the lowest unoccupied molecular orbital (LUMO), interacts more strongly with $\mathrm{O}_{2}$ with respect to other $\mathrm{Au}$ anion clusters larger than $\mathrm{Au}_{8}^{-}$, due to the low electron affinity of $\mathrm{Au}_{20}$ [24]. This suggests that chemically inert 'magic' clusters can become catalytically active with one excess electron. No correlation between geometrical structures of $\mathrm{Au}_{n}^{-}$ and the activities towards $\mathrm{O}_{2}$ adsorption was found, showing that site-specific chemistry disappears for Au-nanocatalysis. By comparing the results from $\mathrm{Au}_{n}^{-}$in the gas phase and those of oxide-supported $\mathrm{Au}$ particles, general pictures for the characteristics of active Au-nanocatalysts and metal-support interactions are drawn.

To synthesize $\mathrm{Au}_{n} \mathrm{O}_{2}^{-}$( $n=$ number of gold atoms), Au clusters were produced in the pulsed arc cluster ion source (PACIS) [11,25], and subsequently exposed to $\mathrm{O}_{2}$. The temperature of the clusters is estimated to be room temperature. The mass of clusters was selected using a time-of-flight (TOF) mass spectrometer, and the ultraviolet photoelectron spectroscopy (UPS) spectra of the mass-selected clusters were taken using UV laser pulse (photon energy $=4.66$ or $6.4 \mathrm{eV}$ ). $\mathrm{AuO}^{-}$ clusters can be also prepared by the reactions between $\mathrm{Au}$ clusters and atomic oxygen created by the dissociation of $\mathrm{O}_{2}$ in the electric arc.

In Fig. 1 the mass spectrum for $\mathrm{Au}_{n}^{-}$after reaction with $\mathrm{O}_{2}$ is demonstrated. $\mathrm{Au}_{n}^{-}$with $n=$ even numbers react with $\mathrm{O}_{2}$ (with an exception of

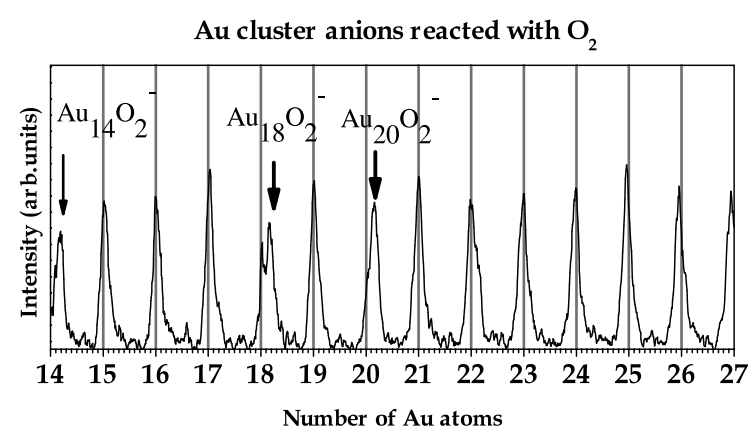

Fig. 1. Mass spectra of $\mathrm{Au}$ anion clusters after reaction with $\mathrm{O}_{2}$. The grid lines correspond to the masses of the pure $\mathrm{Au}$ clusters. Peaks deviating from the grid lines correspond to the reacted clusters.

$\left.\mathrm{Au}_{16}^{-}\right)$, whereas the odd numbered clusters are inert (with an exception of $\mathrm{Au}_{1}^{-}$and $\mathrm{Au}_{3}^{-}$, which partially react) [9-11,26]. Our results are in agreements with this previously observed even/ odd-alteration in the $\mathrm{O}_{2}$ adsorption reactivities, which follows the even/odd-pattern of the electron affinity (EA) of $\mathrm{Au}_{n}^{-}$(EAs of even-numbered $\mathrm{Au}_{n}^{-}$ are lower than those of odd-numbered clusters) $[9-11,26,27]$. It is important to mention that $\mathrm{Au}_{n}^{-}$ with $n=22,24,26 \ldots$ do not react with $\mathrm{O}_{2}$ at all, which can be explained by higher electron affinities of these clusters.

In Fig. 2, the UPS spectra of $\mathrm{Au}_{n} \mathrm{O}_{2}^{-}$(produced in $\mathrm{O}_{2}$ atmosphere) with $n=2-8$ taken using a laser with a photon energy of $4.66 \mathrm{eV}$ are compared. UPS spectra for $\mathrm{Au}_{n} \mathrm{O}_{2}^{-}$with $n=2,4,6$ exhibit vibrational fine structures of about $150-180 \mathrm{meV}$ corresponding to the $\mathrm{O}-\mathrm{O}$ stretching frequencies, indicative of the non-dissociative adsorption of $\mathrm{O}_{2}$. The vibrational frequencies in Fig. 2 are much higher than those found for the di-oxygen species on transition metal surfaces [28]. However, it is important to note that the vibrational frequencies in the UPS spectra correspond to those of neutral clusters with identical geometries to the respective anions. In the anionic states, the additional charge occupies the antibinding orbital of oxygen, further activating the $\mathrm{O}-\mathrm{O}$ bonding, and decreasing the $\mathrm{O}-\mathrm{O}$ stretching frequencies [11]. Thus, the $\mathrm{O}-\mathrm{O}$ vibrational frequency of the anionic state should correspond to those of the peroxo $(80-120 \mathrm{meV})$ or superoxo-species (135-150 meV) [11,28]. 


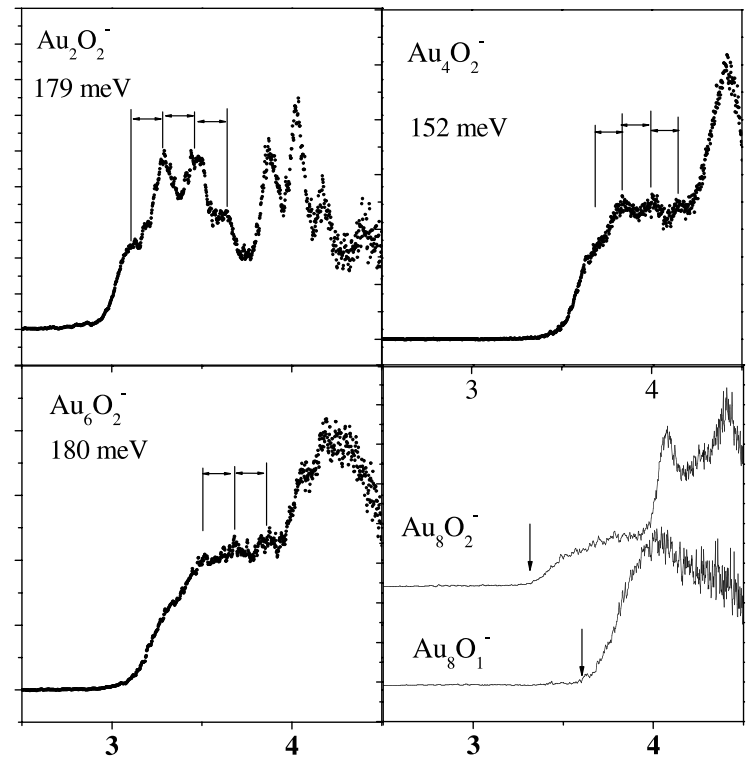

Fig. 2. UPS spectra of $\mathrm{A}_{n} \mathrm{O}_{2}^{-}$for $n=2,4,6,8$, using a laser with a photon energy of $4.66 \mathrm{eV}$. For $n=2,4,6$, vibrational fine structures are resolved, which correspond to the stretching frequencies of di-oxygen species. For $n=8$, no vibrational structures are resolved, however, comparison of the UPS spectra from $\mathrm{Au}_{n} \mathrm{O}^{-}$and $\mathrm{Au}_{n} \mathrm{O}_{2}^{-}$allow to determine that oxygen molecularly adsorb on $\mathrm{Au}_{8}^{-}$.

For $\mathrm{Au}_{8} \mathrm{O}_{2}^{-}$, the vibrational fine structures are hardly resolved in the UPS spectrum. However, information on the adsorption structures of $\mathrm{O}_{2}$ on $\mathrm{Au}_{8}^{-}$can be obtained using electron affinities. In a simple electron transfer model, the formal charges of molecularly adsorbed oxygen are -2 (peroxospecies) or -1 (superoxo-species), and that of atomic oxygen is -2 . For various $\mathrm{Au}_{n} \mathrm{O}_{m}^{-}$ $(n, m=$ integers), the degree of the electron transfer from $\mathrm{Au}$ to oxygen can be arranged in the order of $\mathrm{O}_{2}$ (superoxo, 1e transfer) $<\mathrm{O}_{2}$ (peroxo, 2e), $\mathrm{O}$ (one oxygen atom, $2 \mathrm{e}$ ) $<2 \mathrm{O}$ (two oxygen atoms).

A larger electron transfer from $\mathrm{Au}$ to adsorbates should lead to a higher electron affinity, i.e., by comparing the electron affinities of $\mathrm{Au}_{n} \mathrm{O}^{-}$with those of $\mathrm{Au}_{n} \mathrm{O}_{2}^{-}$, one can identify, if $\mathrm{O}_{2}$ dissociate or not in $\mathrm{Au}_{n} \mathrm{O}_{2}^{-}$. Within this approach, a lower electron affinity of $\mathrm{Au}_{8} \mathrm{O}_{2}^{-}$with respect to that of $\mathrm{Au}_{8} \mathrm{O}^{-}$indicates a molecular adsorption of $\mathrm{O}_{2}$ (Fig. 3). The comparison of the electron affinities of $\mathrm{Au}_{n} \mathrm{O}_{2}^{-}$and $\mathrm{Au}_{n} \mathrm{O}^{-}$for $n=1,2,4,6$ suggests
Group S

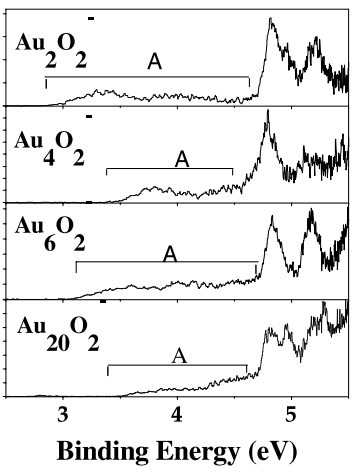

Group W

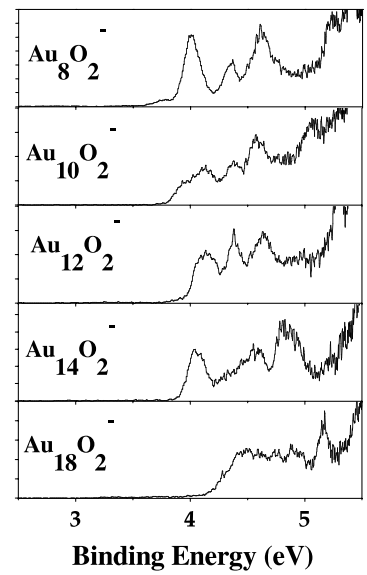

Fig. 3. Left: UPS spectra of $\mathrm{Au}_{n} \mathrm{O}_{2}^{-}$for $n=2,4,6,20$. Right: UPS spectra of $\mathrm{Au}_{n} \mathrm{O}_{2}^{-}$for $n=8-18$. At the bottom, It is important to note that $\mathrm{Au}_{n}^{-}$with $n=8-18$ show higher electron affinities $(<2.75 \mathrm{eV})$ to those of the $\mathrm{Au}_{n}^{-}$with $n=2,4,6,20$.

that $\mathrm{O}_{2}$ dissociatively adsorbs on $\mathrm{Au}^{-}$, but molecularly on $\mathrm{Au}_{2}^{-}, \mathrm{Au}_{4}^{-}$, and $\mathrm{Au}_{6}^{-}$. These results are in agreements with the vibrational fine structures of the UPS spectra (Fig. 2) as well as DFT-calculations [11,21], confirming that electron affinities can be used to determine adsorption structures of $\mathrm{O}_{2}$ on $\mathrm{Au}_{n}^{-}$. It is worth mentioning that molecular adsorption of $\mathrm{O}_{2}$ on other transition metals such as anionic $\mathrm{Cr}$ monomer gives much less increase of the electron affinities with respect to the dissociative adsorption, also supporting our simple electronic model [29]. For larger clusters, measurements on monoxide become difficult due to a reduced resolution of the TOF mass spectrometer with increasing cluster size.

UPS studies using a laser with a photon energy of $4.66 \mathrm{eV}$ are limited to the smaller clusters with $n>10$, since the electron affinities of these larger clusters become very close to the photon energy. To obtain information on electronic structures of $\mathrm{Au}_{n} \mathrm{O}_{2}^{-}$for $n=$ up to 20 with a wider energy range, UPS spectra of $\mathrm{Au}_{n} \mathrm{O}_{2}^{-}$are collected using a laser with a higher photon energy $(6.4 \mathrm{eV})$. (Fig. 3) First, we focus on $\mathrm{Au}_{n} \mathrm{O}_{2}^{-}$clusters with $n=2,4,6$, 20 (these clusters are referred to as group $\mathrm{S}$ ). The group $\mathrm{S}$ clusters generally show relatively low electronic affinities $(\mathrm{EA}<2.75 \mathrm{eV})$ (Table 1) [27]. For the group $\mathrm{S}$ clusters, the distinct features of 
the pure $\mathrm{Au}$ anion clusters existing at the binding energies below about $4.7 \mathrm{eV}$ completely disappear upon $\mathrm{O}_{2}$ adsorption, and broad features between 3 and $4.5 \mathrm{eV}$ (marked with $\mathrm{A}$ in Fig. 3) appear, followed by several narrower peaks. These wide features A in Fig. 3 result from the combination of the $\mathrm{O}_{2} 2 \pi^{*}$-orbitals and the valence occupied molecular orbital (MOs) of $\mathrm{Au}_{n}^{-}$. As mentioned above, $\mathrm{O}_{2}$ molecularly adsorb on $\mathrm{Au}_{n}^{-}$with $n=2,4,6$ (Fig. 2). Based on the similarities in the valence electronic structures (Fig. 3), it can be suggested that $\mathrm{O}_{2}$ is also molecularly bound on $\mathrm{Au}_{20}^{-}$. The very large widths of the peak $\mathrm{A}$ are an evidence for a strong overlap of the $\mathrm{O}_{2}-2 \pi^{*}$ orbitals with the valence electronic levels of $\mathrm{Au}_{n}^{-}$. Note that according to the Franck-Condon profile, a large structural change upon electron excitation results in broad band features. Electron detach-

Table 1

The electron affinities of $\mathrm{Au}_{n}^{-}$and $\mathrm{Au}_{n} \mathrm{O}_{2}^{-}$are summarized

\begin{tabular}{rll}
\hline$n$ & $\mathrm{EA}$ of $\mathrm{Au}_{n}^{-}$ & $\mathrm{EA}$ of $\mathrm{Au}_{n} \mathrm{O}_{2}^{-}$ \\
\hline 2 & 1.7 & 3.0 \\
4 & 2.6 & 3.5 \\
6 & 2.1 & 3.2 \\
8 & 3.0 & 3.6 \\
10 & 2.8 & 3.8 \\
12 & 3.0 & 3.8 \\
14 & 2.8 & 3.9 \\
18 & 3.1 & 4.1 \\
20 & 2.7 & 3.6 \\
\hline
\end{tabular}

Electron affinities are given in $\mathrm{eV} . n$ corresponds to the number of gold atoms in a cluster.

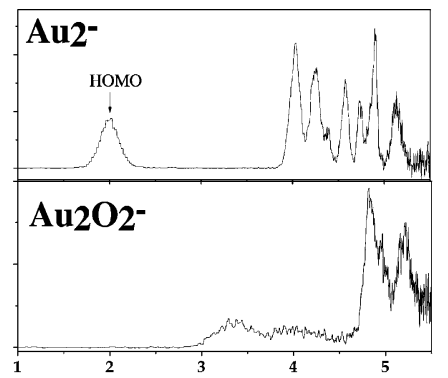

(a) ment can lead to a large structural change, when this electron is involved in a strong chemical bonding in a cluster (in our case $\mathrm{O}_{2}-\mathrm{Au}$ bonding). By comparing the UPS spectra of the $\mathrm{Au}_{n} \mathrm{O}_{2}^{-}$with those of the respective pure $\mathrm{Au}$ anion clusters (Fig. 4), it becomes more obvious that the valence band structure of $\mathrm{Au}_{n}^{-}$is completely changed upon $\mathrm{O}_{2}$ adsorption, confirming significantly large interactions between $\mathrm{O}_{2}$ and the group $\mathrm{S}$ clusters. It should be noted that not only HOMO but also other occupied MOs of $\mathrm{Au}$ anion clusters participate in the $\mathrm{O}_{2}$ chemisorption (Fig. 3, Fig. 5). Most likely, approach of $\mathrm{O}_{2}$ close to $\mathrm{Au}_{n}^{-}$is facilitated by sufficient charge transfers from the delocalized spstate (HOMO) to $\mathrm{O}_{2}-2 \pi^{*}$ orbital, which then enables the contributions of other localized MOs of $\mathrm{Au}_{n}^{-}$with higher binding energies in the $\mathrm{O}_{2}$ chemisorption.

In contrast to the case of group S clusters, UPS spectra of $\mathrm{Au}_{n} \mathrm{O}_{2}^{-}$with $n=8-18$ (group W) consist of distinct multiple peaks (Fig. 3). The peaks from the $\mathrm{HOMO}$ of $\mathrm{Au}$ anion clusters disappear upon $\mathrm{O}_{2}$ adsorption, however, in contrast to the case of the group $\mathrm{S}$, no broad feature is observed in the binding energy regime between 3 and $4.5 \mathrm{eV}$. Only distinct peaks above $4 \mathrm{eV}$ existing in the UPS spectra of the pure Au anion clusters are still visible with minor modifications after $\mathrm{O}_{2}$ adsorption (Fig. 4) [27]. This suggests that a charge transfer from the HOMO of $\mathrm{Au}$ anion clusters to the oxygen is the main chemisorption mechanism, whereas additional overlap between $\mathrm{O}_{2}-2 \pi^{*}$ orbitals and other MOs of the Au anion clusters is

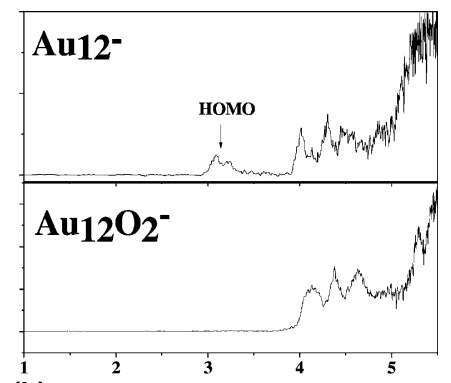

(b)

Fig. 4. (a) As a representative of the group $\mathrm{S}$ clusters in Fig. 3, UPS spectra of $\mathrm{Au}_{2}^{-}$and $\mathrm{Au}_{2} \mathrm{O}_{2}^{-}$are compared to clarify the changes induced by oxygen adsorption for the group $\mathrm{S}$ clusters. (b) As a representative of the group $\mathrm{W}$ clusters in Fig. 3, UPS spectra of $\mathrm{Au}_{12}^{-}$ and $\mathrm{Au}_{12} \mathrm{O}_{2}^{-}$are compared to clarify the changes induced by oxygen adsorption for the group W clusters. 


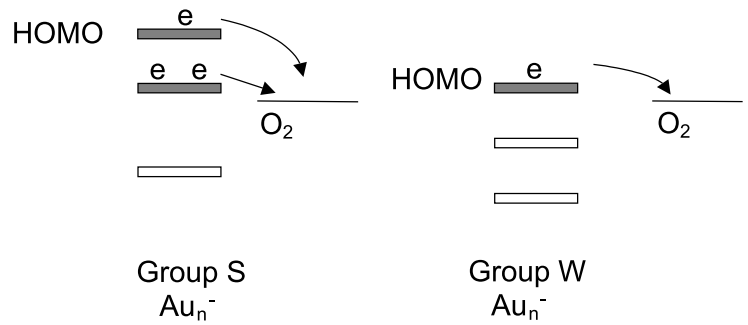

Fig. 5. Simplified orbital schemes for the interactions between $\mathrm{O}_{2}$ and $\mathrm{Au}$ anion clusters.

negligibly small, which is quite different from the result of the group S clusters (Fig. 5). This result is evidence for the much weaker interactions between $\mathrm{O}_{2}$ and group $\mathrm{W}$ clusters with respect to the group $\mathrm{S}$ clusters. General trend for the weaker interactions of group W clusters with $\mathrm{O}_{2}$ is consistent with the recent results from $\mathrm{O}_{2}$ adsorption reactivity experiments on $\mathrm{Au}$ anion clusters [9]. Much weaker interactions between $\mathrm{O}_{2}$ and group $\mathrm{W}$ clusters imply that $\mathrm{O}_{2}$ should not dissociate on these Au anion clusters, since for the dissociative adsorption, stronger $\mathrm{Au}-\mathrm{O}_{2}$ interactions are required. Changes of the electron affinities of the $\mathrm{W}$ group clusters upon $\mathrm{O}_{2}$ adsorption are similar to the case of the $\mathrm{S}$ group clusters, also suggesting molecular adsorption of oxygen on group $\mathrm{W}$ Au anion clusters (Table 1). That the Au anion clusters in group W react more weakly with $\mathrm{O}_{2}$ than group $\mathrm{S}$ clusters is explained by lower electron affinities of group $\mathrm{S}$ clusters with respect to those in the group W [27]. Within a simple charge transfer model, one can argue that $\mathrm{W}$ group clusters allow less $\mathrm{Au} \rightarrow \mathrm{O}_{2}$ charge transfer than $\mathrm{S}$ group clusters.

It is interesting to note that $\mathrm{O}_{2}$ adsorption mechanism on $\mathrm{Au}_{20}^{-}$is much different from those of other $\mathrm{Au}$ anion clusters with similar sizes $\left(\mathrm{Au}_{n}^{-}\right.$ with $n>8$ ), and rather analogous to $\mathrm{O}_{2}$ adsorption pattern of much smaller clusters $(n=2,4,6)$. Recently, $\mathrm{Au}_{20}$ was shown to have a highly symmetric tetrahedral structure with an extremely large HOMO-LUMO gap, i.e. $\mathrm{Au}_{20}$ is classified as 'magic' cluster, suggesting that $\mathrm{Au}_{20}$ should be chemically inert [24]. In general, 'magic' clusters tend to exhibit relatively low electron affinities (note that the electron affinity of $\mathrm{C}_{60}$ is even lower than that of $\mathrm{Au}_{20}$ ) [30], since the energy level of
LUMO is shifted to the lower energy range as a consequence of a large HOMO-LUMO gap. The strong interaction with $\mathrm{Au}_{20}^{-}$with $\mathrm{O}_{2}$ indicates that a 'magic' cluster can become chemically very active with an excess electron, triggering further studies on chemical activities of other 'magic' clusters with one excess electron. It should be emphasized that it is not only the one additional electron in the HOMO of the anionic state of the 'magic' cluster, which participate in the chemisorption. Other MOs in the higher binding energies, which should be chemically inert in the neutral state participate in the chemisorption in the anionic state (Fig. 3).

It should be pointed out that the $2 \mathrm{D}$ to $3 \mathrm{D}$ transitions of the $\mathrm{Au}$ anionic clusters take place at a cluster size of $\mathrm{Au}_{13}^{-}$[31] leading to a highly symmetric tetrahedral (pyramid shape) structure for $\mathrm{Au}_{20}^{-}$[24]. The change of the cluster geometry as a function of size is not reflected in the $\mathrm{O}_{2}$ chemisorption pattern in the present work, indicating that for Au-nanoclusters, site-specific chemistry is absent. It is likely that absence of the size-specific chemistry can be also relevant for other metal nanoclusters.

Comparison of chemisorption properties of $\mathrm{Au}_{n}^{-}$with those of Pt-group metal surfaces provides insights into the origin of the unusual catalytic properties of gold nanoclusters for $\mathrm{CO}$-oxidation and propylene epoxidation. On Ptgroup metal surfaces, $\mathrm{CO}$ oxidation usually takes place through the Langmuir-Hinshelwood mechanism, in which $\mathrm{O}_{2}$ first dissociates and then reacts with $\mathrm{CO}$ to form $\mathrm{CO}_{2}$ [32]. On $\mathrm{Au}$ anion clusters, in contrast, the stabilization of the activated molecular oxygen at room temperature can open new reaction channels (e.g., CO-oxidation mediated by carbonate-like species) [4], responsible for the low temperature $\mathrm{CO}$-oxidation. Molecular adsorption of oxygen can play a vital role for the enhanced activities of gold clusters towards many other catalytic reactions such a partial oxidation of propylene, in which formation of hydroperoxide is suggested to be important [13].

Comparison of the gas phase data and those of the $\mathrm{Au}$ particles on $\mathrm{TiO}_{2}$ can provide a better insight into the role of the support materials in the Au-nanocatalysis. We suggest that support materials in Au-nanocatalyis play the following roles. 
1. Charge transfers from support materials to the $\mathrm{Au}$ particles take place, leading to the increase of the catalytic activities. The gas phase data in the present work indicate that the negative charge on the Au clusters is crucial for the high reactivities. X-ray photoelectron spectroscopy (XPS) results from Au particles on $\mathrm{TiO}_{2}$ in combination with DFT calculations are also in line with the negative charging of the chemically active $\mathrm{Au}$ particle by oxygen vacancies of $\mathrm{TiO}_{2}$ [23].

2. Electronic and geometric structures of Au particles are significantly changed by $\mathrm{TiO}_{2}$. In the gas phase, the HOMO-LUMO gaps of the clusters becomes negligibly small, when the clusters consist of more than about 25-30 atoms [27]. The cluster shape becomes already three-dimensional at a cluster size of $\mathrm{A}_{20}$. In contrast, $\mathrm{Au}$ strongly wets the $\mathrm{TiO}_{2}$ surfaces, keeping the confined thickness of larger clusters to the direction normal to the oxide surface ( $\mathrm{Au}$ initially grows two-dimensional), which increases the contact area between $\mathrm{Au}$ and $\mathrm{TiO}_{2}$ [3]. As a consequence of this metal-support interaction, $\mathrm{Au}$ particles consisting of several hundred $\mathrm{Au}$ atoms (about $2-3 \mathrm{~nm}$ in diameter) are still semiconductive with band gaps up to $1.2 \mathrm{eV}$ [3]. As aforementioned, a larger band gap (or HOMOLUMO gap) of a nanoparticle can cause a lower electron affinity, leading to a higher chemical activity towards $\mathrm{O}_{2}$ adsorption. This can rationalize, why the mean size of catalytically active $\mathrm{Au}$ particles on $\mathrm{TiO}_{2}$ is much larger than that in the gas phase without support.

In summary, we have shown that high chemical activities of $\mathrm{Au}$ nanoclusters result from the stabilization of molecular oxygen on negatively charged $\mathrm{Au}$ clusters with relatively low electron affinities. Interactions of $\mathrm{Au}$ anion clusters with $\mathrm{O}_{2}$ increases with reduced electron affinity. In particular, the anion of $\mathrm{Au}_{20}$, which is a magic cluster with a large HOMO-LUMO gap, becomes more active than other neighboring $\mathrm{Au}$ anion clusters towards $\mathrm{O}_{2}$ chemisorption, indicating that other 'magic' clusters with large HOMO-LUMO gaps are good candidates for building blocks of heterogeneous catalysts with one excess electron. No evidence for the site-specific chemistry was found, and absence of the site-specific chemistry can be relevant for other nanoclusters. We demonstrate that interplay between cluster physics and surface chemistry is a promising strategy to unveil mechanisms of elementary steps on various nanocatalysts. Moreover, a direct comparison between the data from gas phase clusters and supported particles provides a better understanding for the metal-support interactions.

\section{Acknowledgements}

We acknowledge the financial support from DFG (Deutsche Forschungsgemeinschaft). D.W. Goodman is acknowledged for the fruitful discussion.

\section{References}

[1] P. Schwerdtfeger, Angew. Chem. 42 (2003) 1892.

[2] A. Cho, Science 299 (2003) 1684.

[3] M. Valden, X. Lai, D.W. Goodman, Science 281 (1998) 1647.

[4] M. Haruta, S. Tsubota, T. Kobayashi, H. Kageyama, M. Genet, B. Delmon, J. Catal. 144 (1993) 175.

[5] M. Okumura, J.M. Coronado, J. Soria, M. Haruta, J.C. Conesa, J. Catal. 203 (2001) 168.

[6] H. Liu, A.I. Kozlov, A.P. Kozlova, T. Shido, K. Asakura, Y. Iwasawa, J. Catal. 185 (1999) 252.

[7] A. Sanchez, S. Abbet, U. Heiz, W.D. Schneider, H. Häkkinen, R.N. Barnett, U. Landman, J. Phys. Chem. A 103 (1999) 9573.

[8] N. Lopez, J..K. Norkov, J. Am. Chem. Soc. 124 (2002) 11262.

[9] B.E. Salisbury, W.T. Wallace, R.L. Whetten, Chem. Phys. 262 (2000) 131.

[10] W.T. Wallace, R.L. Whetten, J. Am. Chem. Soc. 124 (2002) 7499.

[11] D. Stolcic, M. Fischer, G. Gantefiör, Y.D. Kim, Q. Sun, P. Jena, J. Am. Chem. Soc. 125 (2003) 2848.

[12] T.S. Kim, J.D. Stiehl, C.T. Reeves, R.J. Meyer, C.B. Mullins, J. Am. Chem. Soc. 125 (2003) 2018.

[13] T. Hayashi, K. Tanaka, M. Haruta, J. Catal. 178 (1998) 566.

[14] H. Häkkinen, S. Abbet, A. Sanchez, U. Heiz, U. Landman, Angew. Chem. Int. Ed. 115 (42) (2003) 1297.

[15] Z.-P. Liu, P. Hu, A. Alavi, J. Am. Chem. Soc. 124 (2002) 14770.

[16] H.-G. Boyen, G. Kästle, F. Weigl, B. Koslowski, C. Dietrich, P. Ziemann, J.P. Spatz, S. Riethmüller, C. 
Hartmann, M. Möller, G. Schmid, M.G. Garnier, P. Oelhafen, Science 297 (2002) 1533.

[17] H. Häkkinen, U. Landman, J. Am. Chem. Soc. 123 (2001) 9704.

[18] F. Boccuzzi, A. Chiorino, J. Phys. Chem. B 104 (2002) 5414.

[19] V.A. Bondzie, S.C. Parker, C.T. Campbell, J. Vac. Sci. Technol. A 17 (1999) 1717.

[20] J.-D. Grundwaldt, M. Maciejewski, O.S. Becker, P. Fabrizioli, A. Baiker, J. Catal. 186 (1999) 458

[21] G. Mills, M.S. Gordon, H. Metiu, Chem. Phys. Lett. 359 (2002) 493.

[22] C.T. Campbell, S.C. Parker, D.E. Starr, Science 298 (2002) 811.

[23] Z. Yang, R. Wu, D.W. Goodman, Phys. Rev. B 61 (2000) 14066.
[24] J. Li, X. Li, H.-J. Zhai, L.-S. Wang, Science 299 (2003) 864

[25] S. Burkart, N. Blessing, B. Klipp, J. Müller, G. Ganteför, G. Seifert, Chem. Phys. Lett. 301 (1999) 546.

[26] T.H. Lee, K.M. Ervin, J. Phys. Chem. 98 (1994) 10023.

[27] K.J. Taylor, C.L. Pettiette-Hall, O. Cheshnovsky, R.E. Smalley, J. Chem. Phys. 96 (1992) 3319.

[28] H. Steininger, S. Lehwald, H. Ibach, Surf. Sci. 123 (1982) 1.

[29] G.L. Gutsev, P. Jena, H.-J. Zhai, L.-S. Wang, J. Chem. Phys. 115 (2001) 7935.

[30] X..B. Wang, C.F. Ding, L.S. Wang, J. Chem. Phys. 110 (1999) 8217.

[31] H. Häkkinen, M. Moseler, U. Landman, Phys. Rev. Lett. 89 (2002) 033401.

[32] T. Engel, Ertl. G. Adv. Catal. 28 (1979) 1. 